\title{
Presencia de tres tópicos cordobeses en la literatura: La mujer, los toros y San Rafael (I)
}

MARIA JOSE PORRO HERRERA

El mundo del arte suele ser proclive a admitir en su seno el tratamiento de ciertos temas que a fuerza de repetirse y de ir estilizando sus contornos van convirtiéndose paulatinamente en tópicos; pasan, entonces, a ser monedas de uso corriente, patrimonio universal, y a perder el halo de frescura y novedad que les permitió en un principio interesar la atención del creador y ser transformados en objetos artísticos. La literatura no es ajena a este proceso y según épocas, modas y autores ciertos temas se prodigan en las páginas literarias hasta que alguien con autoridad reconocida llega en el momento oportuno para "torcerle el cuello al cisne" o, por el contrario, transformarlo en nueva Ave Fénix resurgidora de sus propias cenizas.

En esta línea hemos querido seguir el rastro libresco que tres tópicos cordobeses -la mujer cordobesa, los toreros y San Rafael- han ido dejando a través del tiempo. Eludimos desde ahora deliberadamente el hacer cualquier tipo de reflexión crítica sobre el particular. No se trata de poner en tela de juicio ni lo apropiado de su utilización, ni la idoneidad de esta temática en autores y obras. Sí queríamos comprobar cómo los tres ejes temáticos aquí seleccionados pueden ser considerados como ciertas aguas correntías que aparecen de súbito tras grandes períodos de estiaje y que si bien parecen resignadas a una suerte de olvido, de ningún modo están dispuestas a renunciar a su cauce primigenio ganado palmo a palmo a través de los tiempos. 


\section{MUJERES}

La mujer cordobesa como realidad tangible, con unas caracteristicas tipológicas perfectamente definidas. ha venido siendo a través del tiempo un "motivo" rayando en el tópico, "motivo" quizá de los más productivos, que ha acudido con regularidad y casi sin excepcion a lia pluma de muchos escritores cordobeses.

A simple vista, y justificada por su evidente profusión, la faceta que sobresale entre todas es aquella que se mueve en los aledaños de las artes plásticas -no en vano fue cordobés el pintor que consagró dentro de las visuales el cliché de la mujer cordobesa, Julio Romero de Torres, lanzándola como prototipo de una ciudad y una raza hacia todas las direcciones de la rosa de los vientos-.

Sus mujeres [las de Julio Romero] inconfundibles tienen el privilegio de ser 'las suyas'. Ningún pintor de España puede jactarse de decir eso: "Mis mujeres". Y además, ha creado un tipo: el de la beldad cordobesa. Las hembras de aquí no obedecen a un patrón único, está claro, ni tienen todas las narices más largas que en el resto de Andalucía, cual asegura cierto etnólogo de pan llevar. Son diferentes: rubias, morenas, como el trigo, blancas, hechas tizones, gordas, huesudas y carabinas o retacos; mas para el mundo, desde el arte de Julio Romero de Torres, la cordobesa es una sola; la del semblante aceitunado, con ojos lebriles y negros, airosa de empaque, y enjuta, con excepción de cierta zona en que su pincel se recrea; y de abandonos melancólicos. ¡Personalidad!.

Sin duda alguna, insistimos, las descripciones plásticas se llevan la palma sobre cualquier otra faceta o cualidad destacable. En ellas, el binomio njos-pelo figura a la cabeza: siguen en interés la tez. las manos $v$ el talle; muy rara vez se alude a la estatura o al pie. El resto de la anatomia femenina es recogido de lorma vaga y generalizada, y esto sin excepción.

Sólo algunos autores incluyen entre sus páginas lo que pudiera servirnos de documento sociológico, al fijarse en el tipo de educación recibido por estas féminas - tanto el real como el deseable--, el hábitat en el que se mueven, etc. De todo ello recogeremos algunos ejemplos 
más adelante. Ahora conviene empezar por lo que dejamos consignado al principio: su belleza estética.

Un antecedente -si bien generalizador- lo encontramos ya en las páginas de La Lozana Andaluza. donde se dice con evidente hipérbole:

Lozana: " ¡Oh qué lindas son! Pasan a cuantas naciones yo he visto, y aún a Violante, la hermosa, en Córdoba!".2

La universalidad del tópico está también en Cristóbal Romero Rodriguez:

"Las mujeres, de Córdoba y Sevilla".3

y en Antonio Jiménez de González:

En el dulce Abogado

de los quereres

¡a mi Córdoba canto!

nido de amores:

¡lindo vergel de rosas

y de mujeres!

porque mujer y rosas...

¡todas son flores!. ${ }^{4}$

Cuna de legendarias

leyendas tiernas

donde mujer y llores...

se complementan.

Veamos ahora algunos ejemplos en los que las descripciones plásticas se centran en rasgos físicos concretos. Comencemos por ojos y pelo (el subrayado de los términos correspondientes es nuestro):

"Porque Soledad (. . ) con sus ojos rasgados y negros como

2 F. Delicado: La Lozana Andaluza, pág. 32.

3 C. Romero Real "En la fuente", en Antologia Poética.

4 A. Jiménez de González: "Mujeres", en Poesias Seleclas, pág. 89.

5 Id. id. pág. 190. 
un cielo tempestuoso, con su tez morena pálida, con sus frescos labios rojos cual fruto de madroñeras, y con su talle ondulante y flexible cual las gallardas palmas, Soledad, repito, era el "presustra" de las buenas mozas cordobesas". 6

En algunas de sus canciones dice Avilés:

"Al ver a las cordobesas, le asombraba á un extranjero que teniendo ojos tan grandes, tuvieran pies tan pequeños".?

Desde Febrero a Noviembre

el sol en Córdoba quema; pero más queman los ojos de las niñas cordobesas". 8

Siguiendo el tópico, M. Góngora Ayustante canta a la

$$
\begin{aligned}
& \text { ". . mujer triste de ojos negros } \\
& \text { y las negras trenzas } " .9
\end{aligned}
$$

Idénticos elementos descriptivos encontramos en el modernismo evocador de N. Díaz de Escobar:

Gozaron en tu seno las hadas los placeres de eterno paraíso, henchido de ventura, y en horas placenteras copiaron tus mujeres de las celestes hadas la mágica hermosura. Sus ojos son destellos del sol en el estío, su esbelto talle copia el ondular incierto de la gentil palmera, cubierta de rocío, que llora a sus hermanas las hijas del desierto.. ${ }^{10}$

6 M. R. Blanco Belmonte: Desde mi celda, págs. 10-11.

7 A. Avilés: Cantares, pág. 19.

8 Id. id. pág. 40.

9 M. Góngora Ayustante: "Córdoba"/A/, 87.

10 N. Draz de Escobar: "Canto a Córdoba"/A/, págs. 59-60. 
La idealización físico-espiritual en consonancia con unos cánones plásticos consagrados, puede leerse en los siguientes versos de M. Iglesias Caballero:

La que en los ojos tiene un negro-acero un negro-golondrina en la cabeza; la que una vez pintó Julio Romero sobre un fondo de sombra y de tristeza. ${ }^{11}$ de los escritores:

Es, sin embargo, el aspecto físico el que más interesa a la pluma "La joven del encierro, sin duda, es arquetipo de belleza o él la ve así por los encantos con que su ilusión la enaltece. La imagina, con preferencia, de proporcionada estatura. Gusta del color de su cutis, que no es ni blanco ni trigueño, cual las espigas candeales. De la redondez de su cara. De la negrura de su pelo. De sus facciones. De sus ojos". ${ }^{12}$

A los aldabonazos, tras la cruceta de la mirilla, resplandecen dos ojos negros que zahorian. ${ }^{13}$

Alta, de lindo talle, de tez de nardo y ojos muy grises, casi verdes -verdes al sol-, cejas doradas y el cabello, en contraste, castaño oscuro, peinado hacia atrás, a la moda del tiempo aquel (. . .) Sus hechuras armoniosas -alta de pechos, y flexible al cinturear, con las caderas de insinuaciones anforinas, los pies de piñón, andaluces, curvos de empeines; los tobillos para dos ajorcas de pulsos, las piernas redondas y ágiles -y el aire gentil y gitano con majestad de señorío con que la vio por vez primera al salir de su casa del Potro le embelesaron los sentidos. Iba de blanco, con jazmines, envuelto el tesoro

11 M. Iglesias Caballero: "Fragmento de Carmen. Canto a Andalucía"/A/, pág. 95.

12 S. González Anaya: Los Naranjos..., pág. 982.

13 Id. id. id. 1006. 
del busto en un pañuelo de manila de color de gayomba bordado en negro, y con zapatos primorosos que taconeaban en las piedras. ${ }^{14}$

- ¿Morena?

- Morena de trigo, esto es, morena clara. Los cabos. negros.

- Y con los ojos hermosísimos. Los mismos ojos de la madre, tristes también. ${ }^{15}$

Sucede también que las calidades plásticas de los órganos descritos - ojos, pelo, tez, etc-, pasan a convertirse en símbolos de un modo de ser, de una determinada, irresistible e irrenunciable actitud ante la vida, de identificación con una raza que es algo más que mero aporte genético - una profesión de vida:

Mujeres sensuales que en las rejas cantan las noches de luna; mujeres morenas, con ojos fatales, con el fatalismo del alma moruna. Pupilas extáticas entre las ojeras; mujeres ardientes, mujeres dramáticas, como los sollozos de las peteneras.

¡Alma cordobesa, triste y soñadora! sobre tus mujeres parece que pesa la leyenda mora. ${ }^{16}$

Soñadora, en mi mente viviste noche y día, vine á estas tierras santas, sólo por admirarte, . sólo por bendecirte, sólo por adorarte, soñadora y hermana de la melancolía.

14 Id. id. id. 1014.

15 Id. id. id. 1054.

16 E. Carrere: "Córdoba"/A/, pág. 82. 
¡Mujer enaltecida, mujer siempre adorada, mujer toda de encantos, mujer idealizada. en la paleta mágica de Romero de Torres!... ${ }^{17}$

Rico pan de esta carne morena, moldeada en un aire caricia de suspiro y aroma... Sirena encantadora y amante fascinada, los cuellos enarcados, de sierpe o de paloma...

Vuestros nombres, de menta y de ilusión, sabemos: Carmen, Lola, Rosario... Evocación del goce, Adela... Las mujeres que todos conocemos, que todos conocemos iy nadie las conoce! Naranjos, limoneros, jardines, olivares, lujuria de la tierra, divina y sensual, que vigila la augusta presencia del ciprés. En este fondo, esencia de flores y cantares, os fijó para siempre el pincel inmortal de nuestro inenarrable Leonardo cordobés. ${ }^{18}$

"Mocitas de Andalucía, morenas hoy, de ayer moras (. . . si son moras todavía!)".19

"De ahí que te busque arañando ruinas $(. .$. como te apareces equívoca en los ojos morenos, en las romas raíces y redondeces de las muchachas de piel de oliva de mi región, en mi país meridional".20 J. Ma Alvariño: Canciones Morenas, pág. 89. 
"En Córdoba se adunan dos gracias soberanas que dan a sus mujeres aspecto encantador haciendo de ellas rosas de las del campo hermanas, los ojos de sus bellas y lánguidas sultanas, y el tipo de las Vírgenes que adoran al Señor". ${ }^{21}$

"- Fijate ahora -itera Enrique- en ese grupo que se retira de la fuente.

Son tres muchachas con sus cántaros en el cuadril.

- Tienen el garbo, y la esbeltez, y la armonía de las mujeres orientales. Ojos rasgados y profundos, con las negruras de la estirpe. Rostros curtidos por los soles de los desiertos de la Siria. Caderas redondeadas de estatua". ${ }^{22}$

No falta tampoco la mujer-ornato, elemento multicolor más de un conjunto abigarrado y variopinto:
"Muere la tarde, y se explaya
el gentío por la feria
donde mil carruajes pasan
conduciendo a las mujeres
que son de Córdoba gala, en cárcel de seda y raso
presas sus formas gallardas". 23

Aunque mucho más interesante, sin duda, sea la pintura brillante y exquisita que hace Manuel Reina:
"Brillante piel de rico terciopelo, fina y deslumbradora cabellera, provocativa risa, faz de cielo, planta breve y ligera. Boca nido de perlas y ambrosía,

22 S. González Anaya: Los Naranjos... pág. 986.

23 J. Valdelomar: Luz Meridional: "La feria de Córdoba", pág. 45. 
formas esculturales, labios rojos, la hermosa luz del sol del mediodía en los rasgados ojos.

Mundo de amor, tesoro de ternura, cielo de gracias, risas y colores, alma pronta al placer y a la aventura, y pasión por las flores".

Idéntico tratamiento literario se observa en Pío Baroja, si bien el autor noventayochista sólo se apunta a una línea ya conocida y sin que esta faceta por nosotros estudiada le interese muy especialmente, aludiendo a ella sólo de pasada:

A veces, a través de una reja, se verá una cara pálida, anémica, con unos ozajos negros y tristes y una flor blanca en el ébano del cabello.

- ¡Oh! ¡Oh! -exclamaba Matignon, acercándose inmediatamente a la reja.

La muchacha, ofendida de esta curiosidad, dejaba caer el visillo y seguía bordando o cosiendo, esperando al apuesto galán, que quizá no llegaba nunca. ${ }^{25}$

Deliberadamente hemos ido dejando a un lado el tratamiento que don Juan Valera hace de la mujer cordobesa en sus novelas. Con frecuencia suele decirse que sólo él escapa al tópico de los ojos negros y la tez morena; que sus heroínas - Pepita Jiménez, Doña Luz, Mariquita-, son rubias, pese a su indiscutible andalucismo interior. Todo ello vendría ratificado por ejemplos de descripciones como las que se insertan seguidamente:

"Doña luz era un sol que estaba en el cenit. Gallarda y esbelta, tenía toda la amplitud, robustez y majestad que son compatibles con la elegancia de formas de una doncella llena de distinción aristocrática. La salud brillaba en sus frescas y sonrosadas mejillas; la calma, en su cándida y tersa frente, coronada de rubios rizos; la serenidad de su espíritu, en sus ojos azules, donde cierto fulgor apacible de caridad y de sentiReina, págs. 117-118. 
mientos piadosos suavizaba el infinito orgullo". ${ }^{26}$

y unas páginas más adelante:

Estaba Doña Luz vestida con una linda bata, y los cabellos rubios, no peinados aún, recogidos en red sutil. ${ }^{27}$

y también:

"Sus ojos, azules como el cielo, no revelan sino ideas y sentimientos llenos de limpia honestidad".2s

De Pepita Jiménez se dice que

"en la cabeza no ostentaba tocado, ni flor, ni joya, ni más adorno que el de sus propios cabellos rubios". ${ }^{29}$

“... Apenas si se atreve a decir a Pepita buenos ojos tienes; y en verdad que si lo dijese no mentiria, porque los tiene grandes, verdes como los de Circe, hermosos y rasgados". ${ }^{30}$

“... a no ponerme en ridículo, cerrando en sus presencia los ojos, fuerza es que yo vea y note la hermosura de los suyos, lo blanco, sonrosado y limpio de su tez..."."31

"Ya los hoyuelos de sus mejillas cuando sonríe, ya la blancura sonrosada de su tez..."."32

"Su cabello, rubio, mal peinado aún, parecía más hermoso en su mismo desorden". 33

26 J. Valera: Doña Luz, (O. C. I.), pág. 36.

27 Id. id. id. 47.

28 Id. id. id. 91.

29 Id. id. Pepita Jiménez. (O. C. I.), pág. 129.

30 Id. id. id. 130.

31 Id. id. id. 135.

32 Id. id. id. 148.

33 Id. id. id. 154. 
"Mariquita (. . ) era rubia como unas candelas; su pelo parecía una madeja de hilos de oro; sus labios, una clavellina entreabierta, y sus dientes, por lo blancos, más que perlas, pelados piñones. Sus maños (. . .). Estaba doña Mariquita pálida y ojerosa siempre; pero tenía dos ojos verdes como los de Circe, gue derramaban por toda su fisonomía una expresión apasionada y cierto resplandor gatuno que hería y cegaba las almas. Al través de su tez, de una transparencia de alabastro, se diria que veía circular por las azules venas una sangre, más que Irquida, vaporosa. Era de mediana esiatura, deigada, airosa, y con unos pies pequeñuelos que daba gloria verlos. De otras mujeres se dice que tienen mucha alma en los ojos y en la 11. sonomía ésta tenía alma en todo su cuerpo, en sus monimientos y en su voz".

Sin embargo, no siempre y con toda rigurosidad esto es así: Juanita la Larga, la Doña Mencía de El cautivo de Doña Mencía, la "Inmortal Amiga" de Las Ilusiones del Doctor Faustino, La Calitea de La buena, son morenas, sus ojos negros, dentro de la más ortodoxa estética femenil cordobesa:

"Era ya Juanita una guapa moza en toda la extensión de la palabra. (...) Su pelo, negro, con reflejos azules, estaba bien cuidado y limpio. No ponia en él ni aceite de almendras dulces ni blandurilla de ninguna clase, sino agua sola con alguna infusión de hierbas olorosas para lavarlo mejor. Lo llevaba recogido, muy alto sobre el colodrillo, en trenza que, atada luego, formaba un moño en fingura de dos triángulos equiláteros que se tocaban en uno de los vértices. Como Juanita decía que cabeza loca no quiere toca, casi siempre iba a la fuente sin pañuelo en la cabeza, luciendo así el primor y la pulcritud de su peinado y dejando ver lo bien plantada que estaba la cabeza sobre su airoso cuello, sólo sombreado por algunos ricillos menudos, que se sustraian a la cautividad en que tenían el moño los más largos cabellos. Por delante, recogido el pelo, dejaba ver la tersa frente, recia y chiquita, y sobre las sienes tenía grandes rizos sostenidos con horqui- 
llas...".35

"Se decía que sus cabellos eran negros como la endrina, que los ojos brillaban como dos soles, que tenía manos muy bellas y señoriales y que la palidez mate de su torso y blanco rostro estaba suavemente mitigada por el sonrosado y vago matiz que arrebolaba sus frescas mejillas". ${ }^{36}$

"En pie, en medio del cuarto, estaba una mujer alta y delgada, toda vestida de negro. Sus cabellos eran también negros, como el ébano. El color de su rostro, trigueño claro. Sus ojos, hermosísimos y del color de los cabellos. Todas sus formas elegantes". ${ }^{37}$

"y dio por resultado a una hermosa nin̄a, ojinegra y morena". 38

Para la estética valeriana las manos sobresalen junto a ojos y cabellos en el conjunto femenino de sus protagonistas:

"Se conoce que cuida mucho sus manos y que tal vez pone alguna vanidad en tenerlas muy blancas y bonitas, con unas uñas lustrosas y sonrosadas".

“... las manos de esta Pepita, que parecen casi diáfanas como el alabastro, si bien con leves tintas sonrosadas, donde cree uno ver circular la sangre pura y sutil, que da a sus venas un ligero tinte azul...".

35 Id. id. Juanita la Larga, (O. C. I.), pág. 538.

36 Id. id. El cautivo de Doña Mencía, (O. C. I.), pág. 1170.

37 Id. id. Las ilusiones del Doctor Faustino, (O. C. I.), pág. 251.

38 Id. id. La Buena fama, (O. C. I.), pág. 1107.

39 Id. id. Pepita Jiménez, pág. 129.

40 Id. id. id. 129. 
“... imposible parece que quien tiene manos como Pepita tenga pensamiento impuro, ni idea grosera, ni proyecto ruin que esté en discordancia con las limpias manos que deben ejecutarlo". 41

"Las manos era, en efecto, tan bellas, más bellas de lo que don Luis había dicho en sus cartas. Su blancura, su transparencia nítida, lo afilado de los dedos, lo sonrosado, pulido y brillante de las uñas de nácar, todo era para volver loco a cualquier hombre". ${ }^{42}$

En Juanita la Larga

"Las faenas caseras no habian estropeado sus lindas y bien torneadas manos...". 43

\section{Mariquita tiene}

"sus manos blancas y delicadísimas, con dedos afilados por el extremo y uñas encanutadas, largas y brillantes como el nácar, hubieran dado envidia a muchas duquesas". 44

Curioso es el tratamiento que Valera hace de la belleza femenina cuando se encuentra con protagosnista y deuteragonista unidas por parentesco o amistad. La antítesis que casi inevitablemente se debe manifestar en sus caracteres va a hacer su aparición igualmente en el aspecto físico de las mismas. Compruébese si no qué es lo que sucede en $E l \mathrm{Co}$ mendador Mendoza, en Las Ilusiones del Doctor Faustino o en Pasarse de listo:

“... en consecuencia de tales observaciones, calificó a su sobrina de bonita y de discreta. Se puede decir que la miró concienzudamente/por primera vez, y vio que era rubia, blanca, con ojos azules, airosa de cuerpo y muy distinguida". ${ }^{45}$

41 Id. id. id. 129.

42 Id. id. id. 157.

43 Id. id. Juanita la Larga, pág. 538.

44 Id, id. Mariquita y Antonio, päg. 949.

45 Id. id. El Comendador Mendoza, pág. 382 . 
"El Comendador, a pesar de sus distracciones, miró a doña Clara con extraordinaria curiosidad. Era una niña de poco más de diez y seis años. El color de su rostro, de un moreno limpio, teñido en las mejillas y en los labios del más fresco carmín. La tez parecía tan suave, delicada y transparente, que al través de ella se imaginaba ver circular la sangre por las venas azules. Los ojos, negros y grandes, estaban casi siempre dormidos y velados por los párpados y las largas y rizadas pestañas; si bien cuando fijaban la mirada y se abrian por completo, brotaba de ellos dulce fuego y luz viva. Todo en doña Clara manifestaba salud y lozanía, $y$, sin embargo, en torno de sus ojos, fingiéndolos mayores y acrecentando su brillantez, se notaba un cerco oscuro, como el morado de un lirio". 45

"Era Rosita perfectamente proporcionada de cuerpo: ni alta ni baja, ni delgada ni gruesa. Su tez, bastante morena, era suave y finísima, y mostraba en las tersas mejillas vivo color de carmín. Sus labios, un poquito abultados, parecían hechos del más rojo coral; y cuando la risa los apartaba, lo cual ocurría a menudo, dejaban ver, en una boca algo grande, unas encías sanas y limpias y dos filas de dientes y muelas blancas, relucientes e iguales. Sombreada un tanto el labio superior de Rosita un bozo sutil, y, como su cabello, negrísimo. Dos oscuros lunares, uno en la mejilla izquierda y otro en la barba, hacían el ef́ecto de dos hermosas matas de bambú en un prado de flores.

Tenía Rosita la frente pequeña y recta, como la de la Venus de Milo, y la nariz de gran belleza plástica, aunque más bien fuerte que afilada. Las cejas, dibujadas lindamente, no eran ni muy claras ni muy espesas, y las pestañas, larguísimas, se doblaban hacia fuera, formando arcos graciosos. El conjunto de todo expresaba una mezcla de malicia, soberbia, imperio, alegría, ternura y deseo de amar, imposible de describir. Ojos negros $y$ ardientes, lánguidos a veces, a veces activos $\mathrm{y}$ fulmíneos como dos ametralladoras, iluminaban aquella movible fisonomia". 47

47 Id. id. Las instones..., pág. 273. 
"Ramoncita, la otra hija del escribano, era blanca, no tenía lunares, tenía la boca pequeña, era más alta que Rosita, y pasaba tambien por más guapa; pero ni en media docena de años revelaba Ramoncita, ni al alma ni a los sentidos, lo que Rosita en un momento. Rosita, sólo con mostrarse, daba idea de la gloria y del infierno; Ramoncita, del limbo". 48

"En el rostro iban declarando que eran hermanas (. . .). La mayor de edad y menor de estatura, la del traje de seda, era trigueña, con ojos y pelo negros, labios coloreados como una guinda y blanquísimos dientes, que mostraba riendo. La menor, la del vestido de percal, era bastante más alta; parecía te. ner cuatro o cinco años menos que la otra, dieciocho a lo más; era blanca y rubia, y con ojos azules, y propiamente asemejaba un ángel". ${ }^{\text {. }}$.

No pensemos ni por un momento que la tipología determinará en ellas su temperamento caracteriológico, no. Impetuosas, decididas, activas, $\mathrm{o}$, por el contrario, débiles, ensoñadoras, no lo deben al heço de ser rubias o morenas. Parece más bien como si el autor hubiera necesitado del contraste para subrayar mundos opuestos. De cualquier forma, la minuciosidad con que describe a sus personajes femeninos, la delicadeza con que a ellos se aproxima y el cariño con que recoge su dedicación a las faenas caseras, sus ilusiones, dudas, así como el ímpetu y la voluntariedad de que muchas de ellas hacen gala, convierten a este autor en uno de los que sin duda la palabrería hueca y vana que ha triunfado en otros, mejor y con mayor justeza ha conseguido pintar a la mujer de su tierra.

Tanto en sus novelas andaluzas como en artículos variados - muy singularmente el titulado "La Cordobesa", del que se hace eco Azorín en el capítulo VIII de su libro El paisaje de España visto por los españoles,$- \$ 0$ el cordobés se goza en ofrecernos con minuciosidad deliciosa y detallismo de "connaisseur" una suerte de decálogo en el que puntualiza las características tipológicas de sus paisanas; si bien es cierto

Azorín: "Córdoba", en El paisaje de España visto por los Españoles, Cap. VIII. 
que en un principio Valera se muestra escéptico sobre el hecho mismo de su existencia, su actitud más parece interrogación retórica al gusto de la preceptiva clásica que una dubitación sincera, pues en la página siguiente se apresura a rebatir la afirmación inicial:

"El tipo cordobés femenino no ha desaparecido; pero ha habido cambio, si bien el cambio no ha sido de lo castizo a lo exótico. El cambio ha sido por interior desenvolvimiento de la propia esencia de la mujer cordobesa, la cual, como todas las esencias inmortales, permanece en su fundamento sustancial, si bien adquiere nuevas formas y nuevos accidentes". ${ }^{51}$

En este que hemos dado en denominar decálogo, Valera recoge el aspecto estético sólo como un punto más, y no el primero, dentro de las cualidades antropológicamente definitorias de la genuina cordobesa, "la lugareña", ya sea rica, ya pobre, ya señora, ya criada, sin importar que viva en la ciudad o en el campo: siempre se desenvuelve en los límites que marca su casa o los aledaños inmediatos. La mujer trabajadora, campesina o menestrala, casi no existe: una excepción -y por lo mismo, válida- puede ser Juana la Larga, quien sólo por compromiso sale a hacer faenas fuera de su domicilio y evita que su hija Juanita tenga que hacerlo. Veamos los puntos fundamentales:

1. La lugareña es en extremo hacendosa, vigilante, aseada, cuidosa y esmerada en su economía.

2. Es habilidosa en la cocina, maestra en guisos, pastelera y repostera.

3. Se luce en el manejo interior de la casa: ordena, limpia, enjalbega, engalana los patios y cuida de sus plantas.

4. Tiene a su servicio criadas conocedoras de cuentos y graciosos sabedores de chistes.

5. Ejercita una fidelidad resignada hacia esposos y novios.

6. Muy esporádicamente veleidosa, es "enderezada" sabiamente por los hombres de la casa - padre, o marido- con una buena vara de mimbre.

7. De complexión robusta, ello no empece la esbeltez y gentileza de que goza: fuerte, pero no gorda.

8. La gracia, el garbo y el salero son patrimonio indiscutible de todas ellas. 
9. Modelo de paciencia, todo corazón y ternura, pero sin el sentimiento falso de alquimia que ha venido de extranjis.

10. Profundamente religiosa:

"Entre los hombres ha cundido la impiedad. El soldado licenciado, de retorno a su casa, ha solido traer algún ejemplar del Citador; los periódicos se leen, y no todos son piadosos; y por último, no falta estudiante que vuelve de la Universidad inficionado de Krause, $\mathrm{y}$ hasta de Hegel, y que echa discursos a los rústicos, a ver si los hace panteistas o egoteistas.

La mujer no entiende, ni quiere entender, tan enrevesados tiquismiquis, $\mathrm{y}$ sigue apegada a sus antiguas creencias". ${ }^{52}$

La antonomia conductual religiosa mujer/hombre no es detectada únicamente por el escritor egabrense y así, Salvador González Anaya en Los Naranjos de la Mezquita, se hace eco de similar actitud:

"La joven se prosterna devotamente ante el camarín de la Virgen, requiere al punto su rosario, se persigna y se absorbe con alma y vida en la oración, mientras que Enrique, tras de bisbisar una Salva, se entrega al examen artístico del altar mayor, donde luce un retablo de Churriguera con exceso de entalladuras". 53

Dejando a un lado la faceta que venimos tratando, hay que admitir que, a pesar del protagonismo que ostenta en cierta novela realista y su continuadora, la cordobesa no parece demasiado favorecida por los testimonios que la literatura documenta de otras parcelas de su vida, por ejemplo, en lo que a la educación recibida se refiere. Valera deja constancia de ello principalmente en tres de sus novelas: Las Ilusiones del Doctor Faustino, El Comendador Mendoza y Pepita Jiménez:

"Su claro entendimiento está bastante cultivado; pero su educación ha sido sólida y muy cristiana hasta rayar en la austeridad (. . .). El recogimiento con que ha criado a Constancita una señora, tía suya (. . .) ha sido extraordinario (. . .). Nunca ha leído Constancita ni una sola de esas perversas novelas que ahora se escriben, sino libros de devoción,

52. Id. id. id. 1299-1308.

53 S. González Anaya: Los naranjos.., pág. 1068. 
algo de Historia y mucho de Año Cristiano. Cose y borda con notable primor (. . .) y sabe preparar y condimentar mil deliciosos platos de dulce y repostería, que le enseñan las monjas"s4

"Las dos tías o chachas se parecían en algo y se diferenciaban en mucho.

Se parecían en cierto tono amable y benévolo de hidalgas, en la piedad católica y en la profunda ignorancia. Esto último no provenía sólo de que hubiesen sido educadas en el lugar sino de una idea de entonces. Yo me figuro que nuestros abuelos, hartos de la bachillería femenil (. . .) habían caido en el extremo contrario de empeñarse en que las mujeres no aprendiesen nada. La ciencia en la mujer hubo de considerarse como un manantial de perversión. Así es que en los lugares, en las familias acomodadas y nobles, cuando eran religiosas y morigeradas, se educaban las niñas para que fuesen muy hacendosas, muy arregladas y muy señoras de su casa. Aprendían a cosar, a bordar y a hacer calceta; muchas sabían de cocina; no pocas planchaban perfectamente; pero casi siempre se procuraba que no aprendieran a escribir, y apenas si se les enseñaba a leer de corrido en el Año Cristiano o en algún otro libro devoto". 55

La discreción femenina resulta virtud muy admirada:

"No se puede negar que Pepita Jiménez es discreta (. . .) Habló conmigo de las cosas del lugar, de la labranza, de la última cosecha de vino y de aceite y del modo de mejorar la elaboración del vino; todo ello con modestia y naturalidad, sin mostrar deseos de pasar por muy entendida".ss

Modestas, recatadas, preparadas para desempeñar correctamente el papel que les corresponde según sus status, pero sin salirse de él. Si alguna de ellas se atreve a pasar la barrera de lo socialmente permitido, siquiera sea en minúsculas dosis, el autor se considera obligado a intervenir a su favor para dejar constancia de que la protagonista actúa, no 
se olvide, "con modestia y naturalidad, sin deseos de pasar por muy entendida", o en el caso de Juanita la Larga

"la misma libertad en que se había criado, y el constante ejercicio corporal, ya en útiles faenas, ya en juegos más de muchacho que de niña, habian hecho que Juanita, aunque no tenía la santa ignorancia, ni había vivido con el recogimiento que recomiendan y procuran otras madres celosas, no había pensado todavían en cosas de amor". ${ }^{57}$

Interesante resulta la lectura del pasaje en que el escritor describe a la madre del protagonista de Pasarse de listo. ¿Cómo conciliar el que la condesa fuera "una gran señora (. . .) muy al gusto antiguo" $\mathrm{y}$ el hecho de no estar "muy en contra de esto que llaman el espíritu del siglo"?. Conozcámoslo en palabras del autor:

"La condesa era una señora en toda la extensión de la palabra y muy al gusto antiguo. Estaba más cerca de los cincuenta que de los cuarenta años, si bien conservando no pocos restos de su en otro tiempo admirada hermosura. Se vestía con severa elegancia y notable' sencillez. Era religiosa sin afectación ni fanatismo. Y no estaba muy en contra de esto que llaman el espíritu del siglo, aunque lamentaba que la aristocracia española careciese de espíritu de clase y fuese, por tanto, incapaz de ser contada como un elemento político, por más que, considerados aisladamente, no valgan menos bastantes individuos de los que a ella pertenecen que muchos de aquellos que se encaraman a las más altas posiciones y mandan y gobiernan, partiendo desde los más humildes puntos de la esfera social.

Ni por esto andaba desavenida la condesa con la época en que vimos, porque percibia claramente que la invasión y encubrimiento de plebeyos astutos venía de muy atrás y no era cosa del día. La aristocracia, creía ella, que dormitaba siglos hacía en dorada servidumbre, y que, contenta o resignada con vanas distinciones áulicas, dejaba el influjo y el mando a los Cisneros, los Pérez y los Vázquez, habiendo sido España una democracia frailuna, y ganando ahora con ser algo parecido a una mesocracia seglar. 
a rezar a la Virgen; y algunos días a la devoción del Sagrario, como esta mañana. Eso es todo. ${ }^{61}$

$\mathrm{Y}$ es la misma literatura la que, moviéndose reiteradamente en el tópico, no podía por menos que apuntar levemente esos defectos que, precisamente por ser patrimonio del sexo en cualquier lugar y época, no desdicen de figurar encarnados entre las hembras de esta tierra:

Siendo mujer, será preciso poner en cuarentena lo que asegures. En la mujer existe siempre, en estado difuso, latente anhelo, $\mathrm{y}$ añadiré que necesario, de hacerse interesante de todos modos. Esta propensión os induce a deformar los accidentes de vuestro vivir cotidiano; y al advenir la circunstancia de oportunidad, lo difuso se concreta rápidamente; y entonces, mentís sin escrúpulos. ${ }^{62}$

- ¡Feminidad! Tú eres maestra de todas las artes del dolo. ¡La Lozana Andaluza, que era de Córdoba, no ideó fraudes tan sutiles como esta mujer prodigiosa!. ${ }^{63}$

Cuando la regla se transgrede, puede decirse que los valores autóctonos han sucumbido; el culpable es casi siempre el gusto por lo foráneo que deposita una pátina de artificiosidad, engaño y mentira sobre lo natural, pudiendo llegar a hacer la figura incluso casi irreconocible:

De los tres retoños de Argote - (. .)- únicamente Ana Ma perduraba en la casa (. . .). La joven era una alhajita casera en lo hacendosa, diligente, pulcra y atenta a todo lo de su padre, salvo un defecto irreprimible: el de ser un tantico derrochadora. Y, además, otro, disculpable: el de estar satisfecha de su palmito y de su rostro picaresco de finas cejas depiladas - cejas de Marlene, la enigmática-, de cutis entintado de camomila con matiz de tabaco rubio, de ojos magníficos y grises, pecadores labios de guinda, y de cabellos de platino, como las bellezas en serie que Hollywood arroja sobre nosotros desde las pantallas del cine. ${ }^{64}$

61 S. Gonzâlez Anaya: Los naranjos..., pág. 984.

62 Id. id. id. 1059.

63 Id.id.id.1013.

64 Id. id. id. 961 . 
... esa dama salió de Córdoba con poco más de quince abxiles (. . .). Por entonces era una nena arrogante, bonita, sin coloretes y con la pálida blancura de los amahares olorosos. Usaba faldillas baratas y un pañuelo de talle muy llamativo, gayomba y negro.

(. .) Siempre tuwo -añora el Morqués- linco talle y majes. tad de señorio. Su padre exa un platero de los de punta entre los mejores de Córdoba. Al ver su carito de ángel y sus ojazos de esmeralda, cuando era un redrojo, deciamos a Valdenebros los tertulios de la caberna del Bolillo (. . ) Esta alhaja con uñas es lo más fino que ha salido de tus talleres.

- De su bellisima persona, ya hecha una mujer de cir. cunstancias, que hable "La niña del zapato" (. .). Thene la piel de nardo puro y los contomos de una estatua, sin crasitud y sin flaquezas. $Y$ con los senos firmes, como a mi padre le gustaba pintarios.

(. . Y) Ya no es aquella niña de carita de ángel (..) ni la chiquita buena que a usied le tuwo - (. . .)- hecho un pirulo de la Alcarria; ni siquiera la artista de los fandangos que desnudó mi padre para su gloxia; sino otra mujer. ¿La recuerda? Blanca, con ojos grises, al sol muy verdes; y con las cejitas de oro, pero con el cabello castaño oscuro.

(. . .) Pues ahora viene convertida en dama de cine, con tues. te de sol, o de química, y aire de mar, esto es, un cobre tirando a rojo; y en los párpados, sombras de azul; y con las cejas pintadas en rayas oblicuas; y los labios bermejos como la sangre.

(. .) y unas pestañas dobles, pero postizas, porque no hay gachí que las tenga de esa longitud y esa curva. Y la melena platino. Le va muy bien.

(. . .) -Más le valiera usar el velo de nuestras mujeres de Córdoba, en especial por las mañanas (. . ), que no esos tocados impropios del garbo andaluz.

- Es que olvidas su condición de aristocracia -adujo don Juan con gracejo-. Nosotros, Ios Marqueses, no nos regimos por las costumbres y los usos de los pueblos semisalvajes. (. . .) - ¿Qué sangre azul, ni que... blasones! El abuelo de "Filigrana" era chalán, en Bujalance, y gitano de los castizos. $Y$ a ella la bautizaron en San Lorenzo, y no en las Calatravas de los Madwies. Además, no debiera destigurarse con hanta pintura de yodo y de carmin y platino, ela, quess grapa sin mejumjes, park segrar a moda curat de las estrellas de los ches, que las hace igtales a todas. Marcharse la piel, que ena banca, 
con aceite de coco, y hacer que el pelo castaño oscuro, y tan bonito, tan de mujer del mediodía, destelle igual que el de una inglesa o una alemana, se me antoja mixtificación censurable. ¡Con lo que por ahí gustan las andaluzas!. ${ }^{65}$

Es cierto que, como acabamos de ver, los autores citados se muestran interesados por la educación y el "modus vivendi" de la cordobesa de su tiempo, pero el rol social desempeñado por la misma permanece dentro de la más estricta ortodoxia conservadora. Por ningún sitio vemos que afloren reivindicaciones laborales ni dentro del hogar ni fuera del mismo: faenas como las campesinas, que sin duda alguna muchas mujeres contemporáneas realizarian, no quedan recogidas por la literatura..$^{65} \mathrm{~b}$

No es sólo Valera quien deja de lado esta faceta; casi podríamos decir que pasa inadvertida para el resto de los autores. Cristóbal Romero en los cuatro primeros versos de su poema "Campesina" parece que, al fin, va a ofrecernos una nueva faceta en el tratamiento del tema. Lamentablemente los cinco versos siguientes vuelven por los fueros de la contemplación plástica, tópica para terminar con un último verso pletórico del folklore más ramplón:

Te vi cogiendo aceituna, luego después escardando y luego te vi segando más ligera que ninguna. En tu cabellera bruna tenías una amapola y una linda caracola en tu nacarada frente $y$ te dije sonriente: ¡viva la gracia española!.66 Id. id. id. 965-966.

65b C. Sánchez Romero, en su libro Doña Mencía. Aspecto físico.., es el único autor que, si bien no de forma especial y sin concretar cifras, alude a la mujer como elemento productor laboral agrario: "En este pueblo hay dos clases de emigración, una periódica que pudiéramos llamar de golondrina, y otra definitiva. La primera se produce desde tiempos muy antiguos, como hemos indicado, a la Campiña de Córdoba, y abarca a unas mil quinientas personas, entre hombres y mujeres". Pág. 140. 
La visión bucólica de Juan Rejano tampoco aporta nada nuevo al aspecto que estamos tratando, pero la belleza lírica y la transparencia de la composición distan mucho de los versos anteriores:

Hortelana del Genil, si yo me volviera noria y pudiera subir agua

a la granada entreabierta de tu boca...

Si me volviera, hortelana, árbol de ramaje espeso para darle sombra al tallo de tu cuerpo...

Si yo fuera agua fresca y sombra pura, ¡hortelana!. ${ }^{67}$

Quizá pudiera decirse que "la mujer nueva" cordobesa, la preconizada desde unos planteamientos ideológicos en los que curiosamente se dan la mano noventayochismo y feminismo, surge de la pluma de Juana Castro, pero su Cóncava mujer no encaja dentro de este estudio por lo que de generalizador y universal encierra, precisamente por no respetar el tópico y despreciar sus estrechos límites, por salirse de ese marco $\tan$ ceñido que amenaza con asfixiar a las figuras que encierra y por la aspiración de esta escritora de ir más lejos y de bucear en los interiores recónditos de "la mujer" sin más, sin connotaciones localistas caracterizadoras.

Y la crítica literaria, ¿qué ha dicho al respecto? porque sabemos que la fuerza de los archisabido, de lo que adquiere categoría de prototipo, puede ser tal que llega a eclipsar y a borrar como en un palimpsesto el diseño original. Es preciso señalar que en general, el tema ha sido despachado con cuatro líneas en las que era más fácil seguir la corriente, dejarse arrastrar por la evocadora fuerza de las imágenes plásticas del otro cordobés universal, Julio Romero de Torres, que detenerse a pensar en los auténticos rasgos antropológicos de la mujer de esta tierra, como ya lo hiciera Valera:

¿Qué diferencia esencial, ni siquiera qué diferencia acciden- 
tal notable puede haber o hay, pongo por caso, entre la corcobesa, la jiennense o la sevillana? Allá en lo antiguo quizá la hubiese, porque no eran tan fáciles las comunicaciones y era más fácil el vivir aislado y sedentario; pero en el día en que, no ya los hombres y mujeres de contiguas provincias, sino los de remotas naciones, longincuos países y apartadísimos reinos, se ven y visitan con frecuencia, icómo ha de persistir esa variedad y distinción de tipos, dando ocasión a que se describan mujeres que por sus costumbres, creencias, modos de sentir y de pensar, fisonomía, continente y traje, se diferencien hasta el punto de que las pinturas o descripciones de ellas se hagan varíen por el asunto y no sólo por a estilo del que pinta o describe?. ${ }^{63}$

Un libro ban prometedor cono el de Luis González López Las mujeres de con fuon Volero, merecedor en su día del premio que lleva el nombre del escritor egabrense, se mueve dentro de las coordenadas a las que ya estamos acostumbrados. Su apotación puede decirse que es nula a este respecto y la paráirasis valeriana constante:

To la imagino (. . .) igual que una cordobesa de hoy, una de las mocttas honestas que trasladó a sus lienzos el pintor fulio Romero (. . .). Córdoba tiene el hechizo de sus mujeres. La tradición musumana -misticismo y sensualidad-, asoma a los ojos grandes, rasgados, abismales de las hembras cordobesas.

(...)

Aunque don luan, su ilustre progenitor, se hubiese propuesto que Pepita jiménez no fuera bonita, lo sería, sí; porque la chicuela representaba el tipo inconfundible de su raza andaluza con las calidades de Córdoba, la llana. El autor, enardecido, fue recreándose en la figura: la encontró vivaz, trajinando en los menesteres cáseros como una hormiga hacendosa; esbelta, dando al aire el porte arrogante de su traza. ${ }^{6}$

Sólo Fernández Montesinos basa el andalucismo de las protagonistas femeninas valerianas en algo más profundo que la mera apariencia

69 L. González López: Las mujeres de Don Juan Valera, págs. 43 y 45. 
estética y dialectal. Azaña no menciona ni siquiera este aspecto. ${ }^{70} \mathrm{Y}$ Carmen Bravo Villasante en Pepita Jiménez, mujer actual ${ }^{71}$, va por otros derroteros.

Nuestro interés por el tema surgió correlacionado con otros dos no menos tópicos dentro de la literatura. Quisimos ver hasta qué punto esta presencia era real.

70 M. Azaña: Ensayos sobre Valera.

71 C. Bravo Villasante: Pepita Jiménez, mujer actual. 
BIBLIOGRAFIA CONSULTADA

AGUILAR PINAL, F.: La obra poética de Manuel Reina, Editora Nacional. Madrid.

ALMEDA, A.: Lúcido en ciernes, Imprenta Ideal. Madrid, 1974.

ALVARINO, J. Ma: Canciones Morenas, Edición de los AmigoeC6rdoba, 1985.

AVILES, A.: Cantares Cordobeses, Sucesores de Rivadeneyra. Madrid, 1898.

AZAÑA, M.: Ensayos sobre Valera, Alianza Editorial. Madrid, 1971.

AZORIN: Obras Selectas, Biblioteca Nueva. Madrid, 1969.

BARO, E.: Las Canciones Intimas, Poesfas. Imprenta de "La Opinión". Córdoba, 1910.

BAROJA, P.: La feria de los discretos, 4 a ed. Rafael Caro Raggio, Editor. Madrid, 1930.

BLANCO BELMONTE (Fray Azogue) M. R.: Desde mi celda. Cuentog, miniaturas, bocetos y legendarias, Imprenta y Librería del "Diario". Córdoba, 1895.

- Homenaje a Córdoba, Ayuntamiento de Córdoba, Córdoba, 1914.

BRAVO VILLASANTE, C.: Pepita Jiménez, mujer actual, Fundación Universitaria Española, Madrid, 1976.

CORDOBA en la poesía. Selección y nota preliminar de Mario López. Ed. "Amigos de Córdoba". Córdoba 1979. Se cita por /A/ en los siguientes autores: - AUMENTE, J.; CARRERE, E.; DIAZ DE ESCOBAR, N.; DLAZ PLAJA, G.; DUYOS, R.;ENTRAMBASAGUAS,J. de.; FERNANDEZ ARDAVIN, L.; GONGORA AYUSTANTE, M.; IGLESIAS CABALLERO, M.; JIMENEZ MARTOS, L.; LAFFON, R.; MACHADO, M.; VALLE, A. del.

DEliCADO, F.; La Lozana Andaluza, Ed. Bruno Damiani. Clásicos Castalia. Madrid, 1972 .

GONZALEZ ANAYA, S.: Obras Completas, Rebelión.- La Sangre de Abel.- El Castillo de irás y no volverás.- Las brujas de la ilusión.- Nido de cigüeñas.- La oración de la tarde. - Nido real de Gavilanes.- Las vestiduras recamadas.- Los naranjos de la Mezquita.- Luna de plata.- Luna de sangre.- El camino invisible.- Las jarras de azucenas. Edt. Biblioteca Nueva. Madrid, 1948. 
GONZALEZ LOPEZ, I.: Las mujeres de Don Juan Valera, Ed. Espasa Calpe. Ma* drid, 1934.

JMMENEZ DE GONZALEZ, A.: Poesías Selectas. Col. de ripios poéticos. Sucesores de Rivadeneyra, Madrid, 1926.

REJANO, J.: Poesías. El Genil y los Olivos. Eds. Demófilo. Córdoba, 1977.

ROMERO REAL, C.: Antología Poética, Ayuntamiento de Fernán Núñez. Córdoba, 1970 .

SANCHEZ ROMERo, C.: Doña Mencta, Aspectos físico, económico y humano, Imprenta Juventud. Baena (Córdoba), 1973.

VALERA, J.: Obras Completas, T. I, II, III, 4a ed. Ed. Aguilar. Madrid, 1958.

VALDELOMAR y FABREGUES, J.: Luz Meridional (Poesías). Imprenta, Libreria y litografía del "Diario". Córdoba, 1889. 